\title{
Creating interaction in online learning: a case study
}

\author{
Kevin J. Downing ${ }^{a}$, Tsz-fung Lam ${ }^{\mathrm{a}}$, Theresa Kwong ${ }^{\mathrm{a}}$, \\ Woo-kyung Downing ${ }^{\mathrm{b}}$ and Sui-wah Chan ${ }^{\mathrm{a}}$ \\ ${ }^{\mathrm{a} C i t y ~ U n i v e r s i t y ~ o f ~ H o n g ~ K o n g, ~ H o n g ~ K o n g ~ S . A . R . ; ~}{ }^{\mathrm{b}}$ Hong Kong Polytechnic \\ University, Hong Kong S.A.R.
}

This paper uses the case-study method to examine detailed data related to student and tutor usage of an asynchronous discussion board as an interactive communication forum during a first-semester associate degree course in applied psychology at the City University of Hong Kong. The paper identifies 'what works' in relation to discussion board use, demonstrating how students might gradually create an online community of their own, but only if prompted in a timely and appropriate way by the course structure. It also identifies three distinct phases in online interaction and suggests these might, to some extent, be mediated by assessment tasks.

\section{Introduction}

Instruction using the Web as a vehicle for content dissemination, and instructorstudent interaction has increasingly dominated debates related to online learning (Nash, 2004). Much of the educational research in this area has focused on examining the importance of teacher-student and student-student interaction in the online learning process, and in particular the use of discussion/bulletin boards to foster the creation of an effective learning environment (Downing \& Chim, 2004a). While some of this research has suggested effective ways of creating such an environment (Chou, 2001; Henri \& Pudelko, 2003; Gilbert \& Dabbagh, 2005), relatively few studies (De Laat \& Lally, 2004; Yukselturk \& Top, 2006) have undertaken detailed week-on-week analysis of tutor and student bulletin board activity throughout a semester, and used these data to make recommendations about how an effective online learning community can be established with appropriate use of the discussion/ bulletin board tools in Blackboard and Web CT.

\footnotetext{
*Corresponding author. Education Development Office, City University of Hong Kong, 83 Tat Chee Avenue, Kowloon Tong, Hong Kong S.A.R. Email: sckevin@cityu.edu.hk
} 


\section{Online versus classroom-based levels of interaction}

There is little doubt that the exponential growth in the use of the Internet and Webbased instruction continues to present educators with considerable opportunities and challenges (Boettcher, 1999; Downing, 2001; McNaught \& Lam, 2005). Among the most frequently cited challenges is concern over a perceived lack of interaction in online educational environments (Hron \& Friedrich, 2003), fuelled by the belief that our 'traditional' classrooms are somehow filled with the vital interactivity that online environments lack. For example, Robertson and Klotz (2002) suggest that the literature provides evidence that online courses are often configured and delivered in a style more often associated with independent study and that, while this format might work in some instances, it leaves what they term a 'missing link' in student learning. They assert that students in an online learning environment lack the opportunity to experience the benefits of both structured dialogue and a sense of community that can be created in a traditional on-site classroom environment. Others (Cook, 2000; Seabolt \& Arends, 2000; Muirhead, 2001) support this view that the interactivity of the traditional classroom is a vital, yet missing, part of Web-based instruction, suggesting that online interaction is somehow flawed because it does not allow for the social and emotional interaction allegedly taking place in traditional classrooms. Some researchers (Downing \& Chim, 2004b) have taken a slightly different viewpoint and investigated the relationship between personality type and different learning environments, suggesting that classroom-based 'introverts' behave more like 'extraverts' when involved in online discussion forums and are more active in online discussions than when based in the classroom.

\section{Synchronous versus asynchronous discussion boards}

In identifying the critical difference between synchronous (fixed time) and asynchronous (anytime, anywhere) discussions, Boaz et al. (1999) refer to the growth of online 'chat' as evidence of the potential value of synchronous online discussion activity. Synchronous methods are those that require students to participate in a learning event at a specific time. However, one of the problems of synchronous discussion boards or chat rooms is that they do not always allow time for students to reflect and consider what they want to say, and consequently those students who are more reflective in their learning style can often feel left out. On the other hand, asynchronous discussion boards provide the opportunity for a less pressured learning environment where participants can contribute to debate at a pace that suits them, relatively free of the time constraints normally associated with face-to-face and synchronous learning environments (Downing \& Chim, 2003). This is part of the added-value that can be brought to the learning experience with appropriate use of an asynchronous discussion board tool. In characterising asynchronous learning environments as being able to provide anywhere/anytime learning, Bourne et al. (1997) nonetheless identify what they regard as a wide variety of issues that remain to be resolved in relation to the effective use of asynchronous discussion boards. These include the difficulties of 
encouraging early engagement, the creation of a sense of a learning community and the sustainability of interaction. Those studies that address these areas either focus on ways of reducing the potential social isolation of students through online exchange (Lally \& Barrett, 1999), explore issues related to emergent role development and group awareness (De Laat \& Lally, 2004) or concentrate on the establishment and effectiveness of forums for professional exchange and discussion amongst teachers (Selwyn, 2000).

Therefore, despite the proliferation of debate, and with the possible exception of Salmon's (2000) work, there remains a relative lack of clear information on what works in terms of setting up and sustaining a successful online learning environment using the discussion/bulletin board tool. This study begins to address this by analysis of discussion board activity and subsequent content data for one semester, and attempts to provide insights into the three issues raised by Bourne et al. (1997):

- What works in terms of encouraging early engagement with the asynchronous use of the bulletin/discussion board?

- How does the sense of a learning community develop, and how can this be encouraged?

- What works in terms of sustaining online interaction?

\section{Methods}

The case-study design was chosen in order to explore student-tutor and studentstudent interaction in the creation of an effective online learning community using the discussion/bulletin board tools available within the Blackboard/WebCT Virtual Learning Environment. This is grounded in the work of Garrison and Anderson (2003), who identify three critical 'actors' in the formal educational context of an online discussion board. These are students, teachers and content. However, attention in this study is focused on student-tutor and student-student interaction, and the content of that interaction is defined according to its agreed purpose (using interrater reliability - three raters agreeing with each other about coding decisions). The case study presented uses a detailed week-on-week analysis of tutor and student discussion board activity using Blackboard as the learning platform, from one blended learning course throughout a semester, to identify what works in establishing and maintaining an effective online learning community.

\section{The blended learning 'case'}

According to Valiathan (2002), 'blended learning' is used to describe learning that mixes various event-based activities, including face-to-face classrooms, online learning and self-paced learning. The main tool for accessing the online component of the blended learning course was the learning management system, Blackboard. Blended learning seeks the optimum blend of self-study, teacher-led events and group collaboration, each deployed in a blend of asynchronous or synchronous 
modes, appropriate for the leaning outcomes. The three-credit course selected for this study is constructed of 10 units of learning material with students recommended to spend approximately 10 hours studying each unit. Teaching and learning materials are presented in a variety of formats and include video clips, audio clips, images, animations, URL links, PowerPoint presentations, and formative and summative quizzes. A total of 7 hours and 40 minutes of face-to-face contact is provided via five tutorials that take place in weeks 1, 3, 6, 9 and 12 of a 13-week semester. Each of tutorials one, two, three, and five are 1 hour and 20 minutes in duration, with tutorial four lasting 2 hours and 20 minutes to allow for students summative small-group presentations. A discussion board is provided on the Blackboard learning platform for the online component of the course to allow students to engage in discussion and collaboration with fellow students and the course tutor. The objective here was to encourage participation in online discussion and foster the formation of a virtual learning community.

Gandell et al. (2000) describe the extent of Web use in terms of the impact it has on learning relevance to the course. They categorised the extent of use according to the relevance and importance of learning goals appropriately addressed. Consequently, they identify five categories that represent a continuum of extent of use:

- Minimal. Use of the Web that is neither relevant nor necessary to achieve any explicitly stated course learning goals, and therefore has no impact on courserelated learning.

- Supplemental. Use of the Web that is relevant but not necessary to achieve a few explicitly stated course goals, and therefore does not have much impact on related student learning.

- Integral. Use of the Web that is relevant and contributes to achieving some of the learning goals in the course, and would have a fair impact on student learning.

- Central. Use of the Web that is relevant and necessary to achieve most learning goals in the course, and would have a substantial impact on student learning.

- Exclusive. Use of the Web that is relevant and necessary to achieve all learning goals in the course, and would have a major impact on student learning.

The extent of Web use for this blended learning course is clearly in the exclusive category, in which the use of the Web is both relevant and necessary, and would have a major impact on student learning. The extent of Web use is exclusive (Gandell et al., 2000) because the online materials (units) are both relevant and necessary to achieve all the learning and assessment outcomes.

\section{Participants}

All participants were first-year City University of Hong Kong freshmen on the applied psychology associate degree programme. Students were enrolled in a blended learning applied psychology course, 'Practical Psychology for Everyday Life', which was run during Semester A of 2006 (September-December 2006) and volunteered retrospectively (they were approached after the semester was completed) 
to participate in this study. All students enrolled on this course $(n=32)$ agreed to take part in the study. All participants were of similar academic background, evidenced by their successful application to study applied psychology at associate degree level at City University of Hong Kong. Ten participants were selected as a convenience sample and interviewed in week 17 by a research assistant not involved in teaching the course.

The only tutor for this course was the first author of this paper, a chartered psychologist and teacher with some 25 years' experience as an educator.

\section{Procedure}

The focus of this case study was the discussion board activity and the analysis of what works in terms of encouraging and sustaining discussion board use, and developing a sense of an online learning community. Data related to asynchronous discussion board activity from both tutor and students were captured and retained by a research assistant over a 17-week period, which began when the course was released online one week before the start of the study period, and extended three weeks beyond the 13 weeks of the course duration. This was later analysed on a week-by-week basis to highlight student discussion board activity, and to relate this to tutor discussion board activity, and other prompts built into the asynchronous course materials. The content materials and all assessment tasks for the whole course (10 units) were available from the first day of the semester so that students could learn at a pace with which they were comfortable. Of particular interest were the categories of student-student interaction and student-tutor interaction over the timescale identified above. Using these categories, data were analysed according to four broad emergent themes:

- Student-student interaction for instrumental reasons. This category includes all postings that primarily relate to seeking and giving assistance, with either academic questions related to course materials and content or enquiries about assignments and the structure of the course.

- Student-tutor interaction for instrumental reasons. This category includes all postings that primarily relate to seeking and giving assistance, with either academic questions related to course materials and content or enquiries about assignments and structure of the course.

- Student-student interaction for emotional/social reasons. This category includes all postings that primarily relate to seeking and giving reassurance and assistance, with social or emotional questions/issues related to studying the course.

- Student-tutor interaction for emotional/social reasons. This category includes all postings that primarily relate to seeking and giving reassurance and assistance, with social or emotional questions/issues related to studying the course.

These themes emerged as a result of identifying that the interactions on our discussion boards generally fell into two clear categories and could usefully be classified accordingly. Postings were either primarily instrumental or social/emotional in terms of their purpose (we agreed that more than $95 \%$ of the posting content had to fall 
within the category descriptions above). This classification was surprisingly easy to achieve with no disagreements among the three independent raters, or subsequent blind rating by the author. Interestingly, but beyond the scope of this paper to consider further, these categories also appear in research into coping strategies conducted by Carver et al. (1989).

\section{Results}

Data were analysed over the 17-week period as identified in Figure 1, which shows a line graph of student and tutor discussion board activity. The course begins in week one and ends in week 13, and the overall number of postings can be seen in the table underneath the graph. While the total for each individual week is summed, a line graph is useful here to demonstrate the overall flow of discussion board postings and highlights three emergent phases (weeks $0-3$, weeks $4-9$, and weeks 10-16) marked with the dotted vertical lines.

Data were then analysed cumulatively for the full 17 -week period according to the coding categories identified for this case study. In other words, a matrix summarising student-student and student-tutor interaction for instrumental and social reasons was drawn up as presented in Table 1 following independent rating and categorising by three raters.

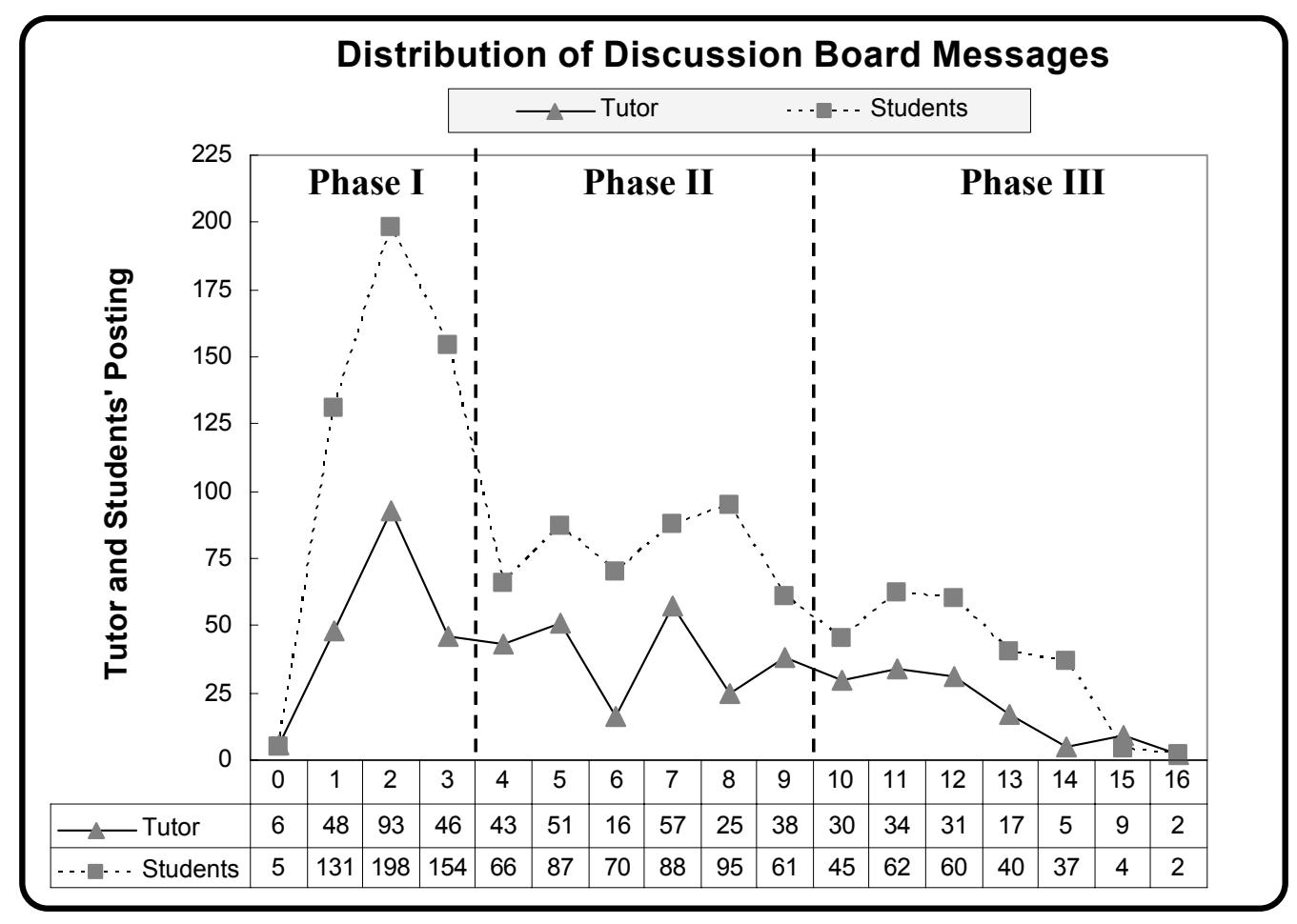

Figure 1. Overall distribution of discussion board postings from week 0 to week 16 
Table 1. Summary of student-student and student-tutor postings for instrumental and social reasons (weeks $0-16$ )

\begin{tabular}{lccr}
\hline & \multicolumn{3}{c}{ Reason } \\
\cline { 2 - 4 } Interaction & Instrumental & Social & Total \\
\hline Student-student & 269 & 564 & 833 \\
Student-tutor & 489 & 434 & 923 \\
Total & 758 & 998 & 1756 \\
\hline
\end{tabular}

\section{Discussion}

Figure 1 and Table 1 show the overall pattern of postings between tutor and student over the 17-week period of this study. What is immediately evident is the degree of parallelism between the two lines, with a notable exception around week eight that will be discussed later. This might be explained by the type and timing of the assessment tasks for this course. Assessment was divided into three components. The first component was participation, which spanned the whole 13-week duration of the course and was worth $20 \%$ of the total marks: $10 \%$ was awarded for in-class participation assessed over the five tutorials and $10 \%$ for online discussion board participation. Students were also required to make a short presentation on a topic in the tutorial for week nine (40\%) and to submit a 2000 -word written paper (40\%) by week 15. The next most notable feature of the data in Figure 1 is the emergence of three distinct phases in terms of posting activity, also identified in Tables 1 and 2 and the summary graph in Figure 2, which appear to be largely driven by the timing and

Table 2. Summary of student-student and student-tutor postings for instrumental and social reasons

\begin{tabular}{lccc}
\hline & \multicolumn{2}{c}{ Reason } \\
\cline { 2 - 4 } Interaction & Instrumental & Social & Total \\
\hline Weeks 0-3 & & & \\
$\quad$ Student-student & 144 & 295 & 382 \\
Student-tutor & 231 & 155 & 299 \\
Total & & 450 & 681 \\
Weeks 4-9 & 116 & & \\
Student-student & 226 & 176 & 292 \\
Student-tutor & 342 & 179 & 695 \\
Total & & 355 & \\
Weeks 10-16 & 66 & & 159 \\
Student-student & 119 & 93 & 219 \\
Student-tutor & 185 & 100 & 378 \\
Total & & 193 & \\
\hline
\end{tabular}




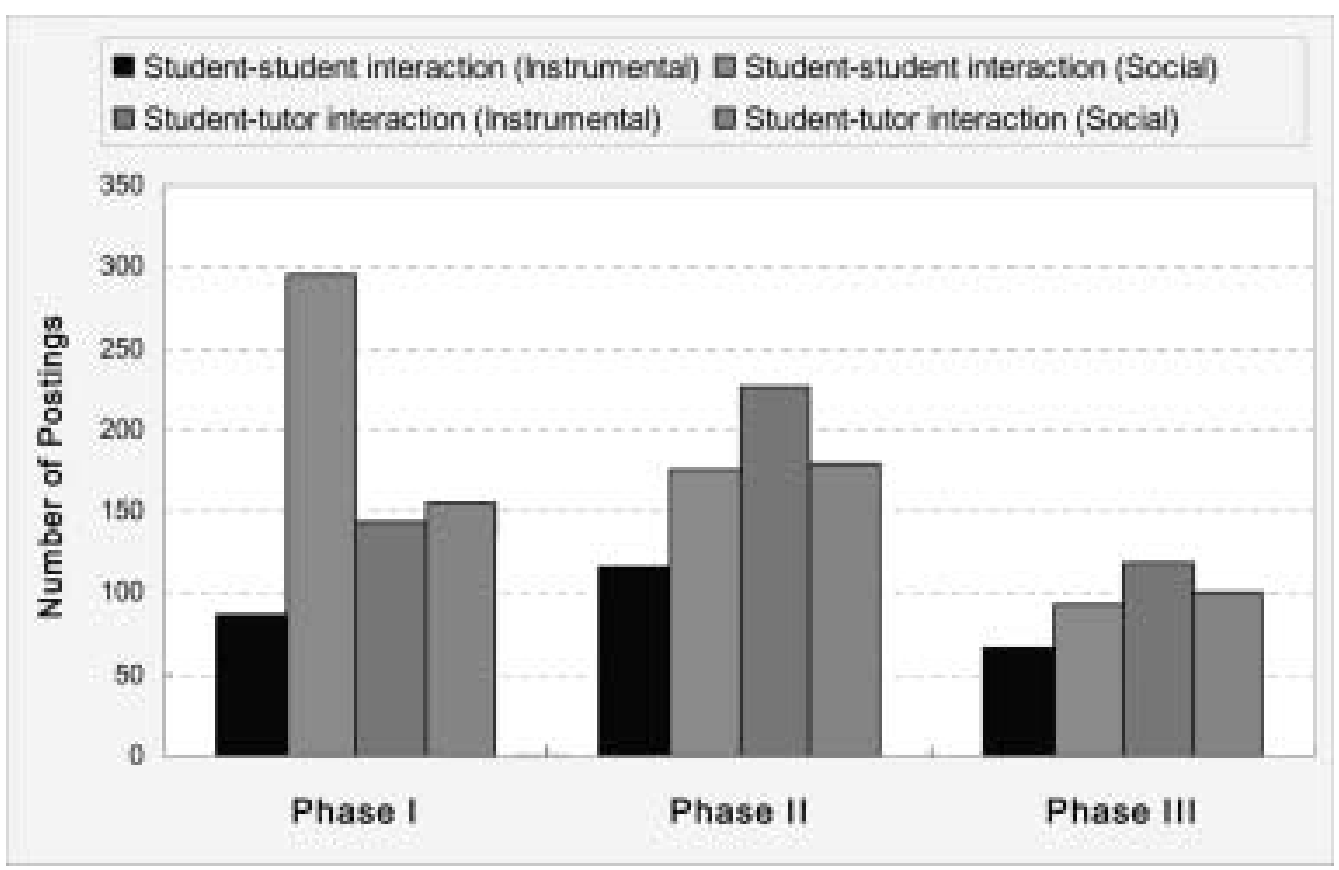

Figure 2. Summary of student-student and student-tutor postings for instrumental and social reasons over the three identified phases (weeks $0-16$ )

nature of formative and summative assessment tasks. These issues are discussed in more detail below.

\section{Phase one: weeks zero to three (socially formative phase)}

The tutor adopted a nurturing and supportive role during the first three weeks of the course, which can be operationally defined as becoming heavily engaged (in terms of providing an encouraging and non-critical response) with students via the online discussion board and ensuring that most tutor postings contained encouraging and supportive comment. This was intended to create a culture of high trust as an appropriate 'climate for learning' (Biggs, 1999). This is evidenced in the tutor postings data in Tables 1 and 2. The intention, then, is for the tutor to gradually withdraw, increasingly responding by acknowledging good questions and reflecting these back to the online student group to encourage metacognitive activity (Downing \& Shin, 2006), further independent discussion and peer learning activity over the remaining 10 weeks of the course. A formative assessment task, due in week three, was designed whereby each student contacted a fellow and posted a short introduction to that individual on the discussion board. The intention of this formative social assignment was to encourage early engagement with the asynchronous use of the discussion board, and to attempt to initiate the beginnings of a sense of a supportive online learning community. The number and nature of student postings during the first three weeks 
of the course demonstrates that this was an effective way of encouraging early engagement with both the discussion board environment and each other. In fact, many of the students, who had been in online contact during this exercise, subsequently chose to sit together from tutorial three until the end of the course. Phase one is characterised by interaction that is largely social in nature, with student-student interaction for social reasons accounting for significantly more postings than the other three categories. The next highest categories are student-tutor interaction for social reasons followed by student-tutor interaction for instrumental reasons. Analysis of the content of the latter category shows most postings to be related to practical course arrangements, tutorials and assignments. The final category was student-student interaction for instrumental reasons, suggesting perhaps that students have not yet sufficiently developed the social relationships with their peers necessary for collaborative learning. A review of student feedback for this semester confirms this assertion, with most student comments identifying the need to build some sort of relationships between each other and the tutor at this early stage. Almost all students identified the early online exercise of contacting and introducing a fellow as very effective in terms of creating a sense of belonging to a group, and only one student commented that he found it 'annoying'. This finding confirms that of Brown (2001), who identifies the first stage of her three-stage model as being about making friends online with whom students felt comfortable communicating. This is very similar to what happens in traditional classrooms where the creation of a safe and supportive learning environment provides an effective context for subsequent learning activity. The social role of the tutor is more clearly defined at this stage than the relationships between students, and this accounts for the significantly higher levels of student-tutor interaction in the social category during this socially formative and somewhat exploratory stage. By week three, all students said that they felt more comfortable in the online discussion board environment; this is confirmed by a notable rise in giving support to their colleagues for instrumental reasons. This is perhaps a form of social learning through modelling the tutors' online social/emotional support behaviours in the manner described by Bandura (1965), and it certainly set the scene for a warm and supportive learning environment both online and in the tutorials. In fact, the importance of developing a sense of trust in the learning environment (McGregor, 1967; Biggs, 1999 ) is identified as being an even more critical success factor in online learning and working environments by Grundy (2002).

The socially formative assessment task to be posted on the discussion board by week three undoubtedly contributed to student-student social interaction during this phase, and substantially assisted in the early stages of relationship building-almost certainly leading to more student-student instrumental interaction in phase two, and setting the scene for a generally high level of overall discussion board activity.

\section{Phase two: weeks four to nine (socially instrumental phase)}

Brown (2001) identifies the second stage as one of community conferment or acceptance, occurring when students are part of a long, thoughtful, threaded discussion on 
a subject of importance. The interactions between weeks four and nine inclusive demonstrate an increase in student-student interaction for instrumental reasons, but this remains the lowest category overall. However, contrary to phase one where social interactions were paramount, this period shows a well balanced mix of both social and instrumental interaction (see Table 2, weeks four to nine). The increase in the student-tutor interaction for instrumental reasons is assignment driven again, this time by the requirement to produce a group summative assignment in the form of a presentation on a selected topic in week nine. Surprisingly, in individual follow-up interviews with 10 of the student participants, seven stated that they began to feel a sense of competition with other groups during this phase and therefore felt more 'comfortable' asking the tutor for help with instrumental matters than their peers/ competitors. All 10 interviewees said that they used private email, rather than the discussion board, to communicate with their fellow presentation group members during this phase. Most gave the reason that they did not want to give away any 'secrets' about their presentation to the other groups. They also admitted being 'careful' about how they phrased discussion board requests to the tutor for instrumental help during this phase so as not to give their 'presentation plans to other groups', and frustrated that the tutor refused to answer queries via email. The tutor refused to answer individual email queries, except of a private/personal nature throughout the course, on the basis that this might encourage more sharing and collaborative learning online. The gradual reduction in student-student interaction for instrumental reasons (see Figure 1) between weeks four and nine is largely a result of students experiencing a sense of inter-group competition given that the presentation assignment due in week nine was summative in nature and carried a substantial proportion $(40 \%)$ of the overall marks for the course. While the overall number of postings during this period is up very slightly on phase one, the distribution of postings according to the four categories is very different and suggests that Brown's (2001) second stage of community conferment or acceptance is compromised when students perceive they are in competition. In fact, the highest number of postings during this phase was student-tutor interaction for instrumental reasons (see Figure 2), which is more consistent with Yuselturk and Top's (2006) 'taskoriented area' classification where instrumental questions take priority over social interaction. Nonetheless, social interaction remained very slightly above instrumental interaction overall, providing evidence that some sense of community prevailed during this phase.

\section{Phase three: weeks 10-16 (withdrawal phase)}

In this phase, both student-student and student-tutor interaction begins to drop away considerably, but a well-balanced mix of social and instrumental postings is maintained. The overall number of postings during this phase is 378 , compared with 697 in phase two, demonstrating that some level of disengagement from the discussion board is taking place. At this stage of the course, students should have completed most of the online course material and be preparing for their individual summative 
written assignment (40\%) due in week 15. All 10 students in the individual follow-up interviews reported that they 'considerably reduced' the frequency of logging on to the online course at this stage, citing final assignment production pressure. This general disengagement with the online learning materials clearly led to a general reduction in discussion board use because students were less likely to be logging into the course to study course materials. This assertion was borne out by course login statistics, which also showed a steady downward trend after week 10 that largely paralleled the reduction in discussion board activity. The follow-up interviews also revealed that once again many students ( 8 out of the 10 interviewed) felt a keen sense of competition with their peers (this time on an individual basis) and preferred to just concentrate on their final written assignment, believing that this would bring them more benefits than continuing to engage in the online discussion board. However, student-tutor interaction remains at phase one levels, with students reporting that maintaining tutor contact to the bitter end was very important and 'might influence their grade positively'. When asked at the interview about this, most students said they were grateful to the tutor for support during the course, and still had some questions to ask in relation to the final assignment, so that is why they had more contact with the tutor than their peers at this stage of the course. However, when pressed, four of the students admitted they thought it 'might influence their final assignment grade'. All but one student said they felt a sense of friendship or community with their fellow students but that this was tempered by the need to get a good individual grade in their final assignment. All 10 of the interviewed students said they would attempt to keep in social contact with at least one of their peers after the course was complete, which suggests some adherence to Brown's (2001) third stage of camaraderie, but one that is much more complex and multi-dimensional than she suggests.

\section{Conclusion}

Some insights have been gained from this case study into the questions posed by Bourne et al. (1997) in terms of what works in facilitating an online discussion board, and some further questions are raised about the complexity of discussion board interaction over the duration of a semester-long course.

Question 1 asked what works in terms of encouraging early engagement with the asynchronous use of the discussion board. There is little doubt from the level of online activity and interaction identified in Figure 1 and Table 1 above that early engagement with an asynchronous discussion board can be greatly facilitated by the design of a simple yet appropriate socially formative assignment. By asking students to contact each other and introduce a fellow student using the discussion board medium, a great deal of early interaction was facilitated. In phase one, there were a total of 681 postings from 32 students (Table 2, weeks zero to three) and these included both student-student and student-tutor interaction, with the emphasis (almost twice as many) being in terms of social interaction. In that sense, and in terms of Brown's (2001) first stage of 'making friends online with whom students felt comfortable communicating', this approach is successful. However, the established 
role of the tutor is clearly important in facilitating a supportive learning environment in the early weeks of establishing an online sense of community.

Question two asked how the sense of a learning community develops, and how this can be encouraged. This is the most problematic question to be answered because, while it might be possible to classify postings as primarily social or instrumental in nature, students will also take into account many other factors before deciding when and what to post. This is evidenced by the data in phase two; and the comments from students in the follow-up interviews, which demonstrate that students are often influenced by what they perceive, are pragmatic considerations about the competition they are involved in when required to complete summative assignments. Despite the fact that the tutor for this course made it very clear from the outset that assessment was criterion referenced, rather than norm-referenced, and that it was therefore possible for every student to be graded ' $A$ ', there was nonetheless a clear formation of separate presentation working groups, and a subsequent reluctance to share too much online with non-group members. In retrospect, this would have been an appropriate time to create separate working groups within the discussion board, rather than to continue with one group to which all students had access. This would have positively influenced the continuation of a sense of a supportive learning community established in phase one. This finding is broadly in agreement with that of Nicol et al. (2003), who point out that the social context of online learning is qualitatively different from more traditional modes and that both practitioners and researchers need to recognise this complexity. In this case study, the timing and handling of the group summative assessment task clearly interfered with the continued establishment of a sense of a supportive and nurturing online learning community, and that if we are to take full advantage of the power of online technologies, we must develop our understanding of their impact upon the social context for online learning.

Question three asked what works in terms of sustaining online interaction, and this is a question that requires some analysis. The results from this study, and others (Brown, 2001; Hwang \& Wang, 2004; Yuselturk \& Top, 2006) suggest that online discussion activity might go through a series of stages or phases, which on the surface might not be too dissimilar to what happens in classroom-based learning. In other words, there is a socially active phase, an instrumental phase and then a gradual, and perhaps natural, process of disengagement. The current study demonstrates that students take a pragmatic approach to this process, disengaging when they feel they have all the information they need to complete the summative assessment tasks they are set. To that extent it is not effective or worthwhile to attempt to sustain online interaction for the duration of the whole course. Provided students have engaged in reflective online discussion activity early on, and completed the online course materials, it might be counter-productive to try to sustain involvement through to the end of the course.

We should interpret sustaining online interaction in a way that adds the provision 'as far as there is educational value in so doing'. If the question is interpreted in this way, educators are provided with much more scope in terms of how they decide to use, and how they evaluate, the success or failure of online discussion forums. 
Vygotsky (1978) pointed out that conceptual learning was a collaborative effort that required supportive dialogue, so it is reasonable to assume that online discussion has the potential to enhance both collaboration and concept development. However, some researchers take the view that true social interaction leading to cognitive growth in an online context is rare (Son, 2002; Meyer, 2003; Wickstrom, 2003), whereas others (Poole, 2000; Grady, 2003; Schallert et al., 2003) demonstrate that significant social interaction leading to effective knowledge construction does take place in online discussion forums. As Kay (2006) points out, a resolution to this debate lies in both the user acceptance of the medium and the amount of structure used to guide the online discussion board. The current study suggests that the former task is perhaps more easily achieved than the latter, and that more research is needed into 'what works' in terms of engaging and sustaining online learning communities that are truly collaborative and supportive.

\section{References}

Bandura, A. (1965) Influence of model's reinforcement contingencies on the acquisition of imitative responses, fournal of Personality and Social Psychology, 1, 589-595.

Biggs, J. (1999) Teaching for quality learning in university (London, Society for Research into Higher Education \& Open University Press).

Boaz, M., Elliott, B., Foshee, D., Hardy, D., Jarmon, C. \& Olcott, D. (1999) Teaching at a distance: a handbook for instructors (Mission Viejo, CA, League for Innovation in the Community College).

Boettcher, J. (1999) Another look at the tower of WWWebble, Syllabus Magazine, 13(3), 50-52.

Bourne, J. R., McMaster, E., Reiger, J. \& Campbell, J. O. (1997) Paradigms for on-line learning: a case study in the design and implementation of an asynchronous learning networks (ALN) course, Fournal of Asynchronous Learning Networks, 1(2), 38-56.

Brown, R. E. (2001) The process of community building in distance learning classes, fournal of Asynchronous Learning Networks, 5(2), 18-35.

Carver, C. S., Scheier, M. F. \& Weintraub, J. K. (1989) Assessing coping strategies: a theoretically based approach, fournal of Personality and Social Psychology, 56(2), 267-283.

Chou, C. C. (2001) Formative evaluation of synchronous CMC systems for a learner-centered online course, Fournal of Interactive Learning Research, 12(2/3), 170-188.

Cook, K. (2000) Computer conferencing really makes the Web interactive, in: E. J. Leach (Ed.) $A$ collection of practices from the league's conference on information technology (Mission Viejo, CA, League for Innovation in the Community College), 132.

De Laat, M. \& Lally, V. (2004) It's not so easy: researching the complexity of emergent participant roles and awareness in asynchronous networked learning discussions, fournal of Computer Assisted Learning, 20, 165-171.

Downing, K. (2001) Information technology, education, and health care: constructivism in the 21st century, Educational Studies, 2(3), 229-235.

Downing, K. J. \& Chim, T. M. (2003) Learning style, student satisfaction and blended learning, paper presented at the Fourteenth International Conference on College Teaching and Learning, Florida Community, Jacksonville, FL, 14-18 April.

Downing, K. J. \& Chim, T. M. (2004a) What are the characteristics of effective online students?, paper presented at the Fifteenth International Conference on College Teaching and Learning, Jacksonville, FL, 29 March-2 April.

Downing, K. J. \& Chim, T. M. (2004b) Reflectors as online extraverts, Educational Studies, 30(3), 265-276. 


\section{K. F. Downing et al.}

Downing, K. J. \& Shin, K. (2006) Developing metacognition with LASSI online, paper presented at the International Conference of the Asia-Pacific Educational Research Association, Hong Kong Institute of Education, Hong Kong, November.

Gandell, T., Weston, C., Finkelstein, A. \& Weiner, L. (2000) Appropriate use of the web in teaching higher education, in: B. L. Mann (Ed.) Perspectives in web course management (Toronto, Canadian Scholar's Press), 61-68.

Garrison, D. R. \& Anderson, T. (2003) E-learning in the 21 st century: a framework for research and practice (London, RoutledgeFalmer).

Gilbert, P. K. \& Dabbagh, N. (2005) How to structure online discussions for meaningful discourse: a case study, British fournal of Educational Technology, 36(1), 5-18.

Grady, D. B. (2003) Mapping online discussions with lexical scores, foumal of Interactive Learning, 14(2), 209-229.

Grundy, J. (2002) Flexible learning and the flexible worker. British Telecom White Paper, December (London, BT).

Henri, F. \& Pudelko B. (2003) Understanding and analysing activity and learning in virtual communities, Fournal of Computer Assisted Learning, 19, 474-487.

Hron, A. \& Friedrich, H. F. (2003) A review of web-based collaborative learning: factors beyond technology, Fournal of Computer Assisted Learning, 19, 70-79.

Hwang, W. Y. \& Wang, C. Y. (2004) A study of learning time patterns in asynchronous learning environments, Fournal of Computer Assisted Learning, 20, 292-304.

Kay, R. H. (2006) Developing a comprehensive metric for assessing discussion board effectiveness, British fournal of Educational Technology, 37(5), 761-783.

Lally, V. \& Barrett, E. (1999) Building a learning community on-line: towards socio-academic interaction, Research Papers in Education, 14(2), 147-163.

McGregor, D. (1967) The professional manager (New York, McGraw-Hill).

McNaught, C. \& Lam, P. (2005) Building an evaluation culture and evidence base for e-learning in three Hong Kong universities, British fournal of Educational Technology, 36(4), 599-614.

Meyer, K. A. (2003) Face-to-face versus threaded discussions: the role of time and higher order thinking, Fournal of Asynchronous Learning Networks, 7(3), 55-65.

Muirhead, B. (2001) Enhancing social interaction in computer-mediated distance education, United States Distance Learning Association Ed at a Distance Magazine and Ed Fournal, 15(40). Available online at: www.usdla.org/html/journal/APR01_Issue/article02.html (accessed 3 April 2007).

Nash, S. S. (2004) New quality benchmarks for online courses: meshing technology and conceptual underpinning, Selected papers from the Fifteenth International Conference on College Teaching and Learning, Jacksonville, FL, 29 March-2 April (The Center for the Advancement of Teaching and Learning, Florida Community College), 195-222.

Nicol, D. J., Minty, I. \& Sinclair, C. (2003) The social dimensions of online learning, Innovations in Education and Teaching International, 40(3), 270-280.

Poole, D. M. (2000) Student participation in a discussion oriented online course: a case study, Fournal of Research on Computing in Education, 33(2), 162-177.

Robertson, T. J. \& Klotz, J. (2002) How can instructors and administrators fill the missing link in online instruction, Online fournal of Distance Learning Administration, 5(4). Available online at: http://www.westga.edu/ dist ance/ojdl a/winter54 /roberson54.htm (accessed 3 April 2007).

Salmon, G. (2000) eModerating: the key to teaching and learning online (London, RoutledgeFalmer).

Schallert, D. L., Reed, J. H. \& D-Team, T. (2003) Intellectual, motivational, textual, and cultural considerations in teaching and learning with computer-mediated discussion, fournal of Research on Technology in Education, 36(2), 103-118.

Seabolt, B. \& Arends, B. (2000) Remaining real in a virtual world. Available online at: http://www. webct.com/service/viewcontentframe?contentID $=2385857 \&$ pageName=index.html (accessed 3 April 2007). 
Selwyn, N. (2000) Creating a 'connected' community? Teachers use of an electronic discussion group, Teachers College Record, 102(4), 750-778.

Son, J. (2002) Online discussion in a CALL course for distance language teachers, CALICO fournal, 20(1), 127-144.

Valiathan, P. (2002) Blended learning models. Available online at: http://www.learningcircuits.org/ 2002/aug2002/valiathan.html (accessed 3 April 2007).

Vygotsky, L. S. (1978) Mind in society: the development of higher psychological processes (Cambridge, MA, Harvard University Press).

Wickstrom, C. D. (2003) A funny thing happened on the way to the forum, fournal of Adolescent and Adult Literacy, 46(5), 414-423.

Yuselturk, E. \& Top, E. (2006) Reconsidering online course discussions: a case study, fournal of Educational Technology Systems, 34(3), 341-367. 